\title{
Kajian Kondisi Faali Sapi Perah Peranakan Fries Holland (PFH) di Peternakan Rakyat Desa Suka Mulya Kecamatan Lembah Seulawah Kabupaten Aceh Besar Provinsi Aceh
}

\author{
(Study on Condition of Dairy Cattle Breed Physiologic Fries Holland \\ (PFH) Livestock in the Village People Prefer Mulya Seulawah Valley \\ District District of Aceh Aceh Province)
}

\author{
Muhammad Junaidi ${ }^{1}$, Cut Intan Novita ${ }^{1}$, Dzarnisa ${ }^{1}$ \\ ${ }^{1}$ Program Studi Peternakan, Fakultas Pertanian, Universitas Syiah Kuala
}

\begin{abstract}
Abstrak. Suatu penelitian telah dilaksanakan di desa Suka Mulya, Kecamatan Lembah Seulawah, Kabupaten Aceh Besar. Penelitian berlangsung dari bulan November sampai Desember 2016. Penelitian ini bertujuan untuk mengetahui kondisi faali sapi Peranakan Fries Holland (PFH) di peternakan rakyat desa Suka Mulya Kecamatan Lembah Seulawah Kabupaten Aceh Besar. Metode penelitian ini bersifat deskriptif analitis dengan mengunakan metode survei dan observasi langsung ke peternak dan sapi perah PFH. Lokasi penelitian ditentukan secara purposive sampling. Penetapan responden ditentukan mengunakan metode random sampling, jumlah responden sebanyak 10 peternak yang memelihara sapi perah. Materi yang digunakan dalam penelitian ini adalah 13 ekor sapi perah PFH. Parameter penelitian meliputi frekuensi pernafasan, denyut jantung dan suhu rektal. Data pendukung yang diperlukan dalam penelitian ini meliputi suhu dan kelembaban kandang, manajemen pemeliharaan sapi perah, kesehatan ternak, dan karakteristik peternak/responden. Hasil penelitian menunjukkan bahwa rataan frekuensi pernafasan sapi PFH adalah28,03 \pm 0,63 kali/menit, frekuensi denyut jantung 68,92 $\pm 0,71 \mathrm{kali} / \mathrm{menit}$ dan suhu rektal $36,57 \pm 0,55{ }^{\circ} \mathrm{C}$. Dari hasil penelitian ini dapat disimpulkan bahwa kondisi faali/fisiologis ternak perah yang ada di peternakan Rakyat Desa Suka Mulya dalam keadaan baik/normal.
\end{abstract}

Kata kunci: Sapi Peranakan Fries Holland (PFH), kondisi faali, frekuensi pernapasan, frekuensi denyut jantung, suhu rectal.

\begin{abstract}
This study aimed to determine the effect of dairy cattle rearing system to physiological conditions in the district of Aceh Besar district seulawah Valley. The method used is descriptive analysis using the method of survey and direct observation to farmers and dairy cows PFH measurement of physiological conditions/physiological. This research by using two stages, the first stage is the observation field conditions and the second stage is the collection of data. Observation phase field conditions to determine the location of the study and the sample size, the data collection phase aims to obtain primary data and secondary data. The research location determined by purposive Desa Suka Mulya. Sampling of cattle that took cattle PFH to measure physiologic conditions/physiological. The number of samples taken in this study there are few dairy cows. The data collected from these samples include respiratory rate, heart rate, rectal temperature. Results of this study was the frequency of breathing 28,03 $\pm 0,63$ times per minute, heart rate $68,92 \pm 0,71$ times per minute, a rectal temperature of $36,57 \pm 0,55$ times per minute. From the results of this research can be concluded that the physiologic conditions/physiological dairy cattle farm in the village of Suka Mulya People in a good state/normal.
\end{abstract}

Keyword: Fries Holland Breed, physiological condition, frekuency of breath, frekuency of pulse hearth, rectal temperatur. 


\section{PENDAHULUAN}

Sapi Perah Peranakan Fries Holland (PFH) merupakan salah satu sapi perah di Indonesia yang merupakan hasil persilangan dari sapi perah Fries Holland (FH) yang berasal dari Belanda dengan sapi lokal. Sapi PFH mewarisi sifat bobot badan cukup tinggi dan mudah beradaptasi dengan lingkungan tropis dengan produksi susu yang relatif tinggi. Namun buruknya manajemen pemeliharaan sapi perah dan kondisi lingkungan menyebabkan produktifitas susu relatif rendah sehingga tidak dapat mencukupi kebutuhan susu dalam negeri (Blakely dan Blade, 1991).

Faktor iklim utama yang berpengaruh terhadap produksi susu antara lain suhu udara, kelembaban dan radiasi matahari. Iklim tropik khususnya di daerah lingkungan lahan kering merupakan salah satu masalah dalam upaya optimalisasi produksi ternak. Tingginya intensitas matahari di wilayah Indonesia menyebabkan suhu udara meningkat, hal ini dapat mengakibatkan sapi perah yang dipelihara akan terkena cekaman panas dan cekaman panas yang ditimbulkan akan berpengaruh negatif terhadap proses faali, produksi maupun reproduksi (Sientje, 2003). Cekaman panas pada sapi perah ditandai dengan meningkatnya denyut jantung, pernafasan, suhu tubuh, konsumsi air minum dan menurunnya konsumsi pakan. Kondisi normal sapi perah dapat tercipta apabila terjadi keseimbangan panas antara produksi dan pelepasan panas. Suhu lingkungan yang tinggi dapat menambah beban panas pada ternak selain panas yang berasal dari proses metabolisme pakan. Kondisi tersebut dapat mengakibatkan ternak mengalami kesulitan dalam pelepasan panas (Umar, et al, 1991).

Dinas Kesehatan Hewan dan Peternakan Provinsi Acehpada tahun 2014 telah mendatangkan 45 ekor sapi perah Peranakan Fries Holland ke daerah Saree Aceh Besar, tepatnya di Desa Suka Mulya Kecamatan Lembah Seulawah Kabupaten Aceh Besar. Daerah Saree memiliki temperatur udara $25-28^{\circ} \mathrm{C}$, kelembaban udara 80- 85,6 \% dan berada di ketinggian 500-700 meter diatas permukaan laut (Aceh Besar Dalam Angka, 2010).

Daerah Saree secara geografis memiliki potensi untuk dikembangkan sapi perah, akan tetapi peternak-peternak yang mendapat bantuan belum terbiasa memelihara sapi perah tersebut, sehingga penelitian untuk melihat kondisi faali sapi Peranakan Fries Holland ( $\mathrm{PFH})$ yang dipelihara oleh peternak dirasa perlu dilakukan.

\section{METODE PENELITIAN}

Penelitian ini dilakukan di Desa Suka Mulya Kecamatan Lembah Seulawah Aceh Besar dari bulan November sampai bulan Desember 2015.

\section{MATERI DAN METODE}

\section{Sapi Peranakan Fries Holland (PFH)}

Materi yang digunakan dalam penelitian ini adalah 13 ekor sapi perah PFH betina di peternakan rakyat Desa Suka Mulya. 


\section{Metode Penelitian}

Metode penelitian ini bersifat deskriptif analitis dengan mengunakan metode survey dan observasi langsung ke peternak dan sapi PFH yang akan diteliti.

\section{Alat dan Bahan Penelitian}

Adapun alat yang digunakan selama penelitian dilapangan adalah kamera, daftar kuisioner, alat tulis, hygrometer, stetoskop, termometer klinik.

\section{Parameter yang Diamati}

Parameter yang diamati pada penelitian ini adalah frekuensi pernafasan, suhu rektal dan denyut jantung yang dilakukan pada sapi Peranakan Fries Holland.

\section{Frekuensi Pernafasan}

Pengambilan data frekuensi pernafasan pada sapi perah dilakukan dengan mendekatkan punggung telapak tangan pada hidung ternak hingga terasa hembusan napasnya. Perlakuan tersebut dilakukan selama 1 (satu) menit dan diulangi sebanyak 3 (tiga) kali lalu hasilnya dirata - ratakan.

\section{Frekuensi Denyut Jantung}

Pengukuran denyut jantung pada sapi perah dilakukan dengan cara meraba pangkal paha kaki depan hingga terasa denyut arteri femuralisnya, kemudian menempelkan stetoskop pada bagian dadanya hingga terdengar denyut jantungnya. Masing - masing perlakuan dilakukan selama1 (satu) menit dan diulangi sebanyak 3 (tiga) kali lalu hasilnya dirata-ratakan.

\section{Suhu Rektal Sapi Perah}

Pengukuran temperatur rektal pada sapi perah dilakukan menggunakan termometer klinik. Awalnya skala pada termometer dinolkan dengan cara dikibaskibaskan dengan hati-hati. Sepertiga bagian ujung termometer dimasukkan ke dalam rektum probandus untuk diukur temperatur rektalnya. Perlakuan dilakukan selama 1 (satu) menit dan diulangi sebanyak 3 (tiga) kali lalu hasilnya dirataratakan.

\section{Pengumpulan Data Pendukung}

Data pendukung yang diperlukan dalam penelitian ini meliputi:

1. Keadaan lokasi penelitian yang meliputi suhu dan kelembaban kandang

2. Manajemen pemeliharaan sapi perah.

3. Kesehatan ternak, meliputi pengendalian penyakit, sanitasi perkandangan, dan vaksinasi.

4. Karakteristik peternak/responden.

Kegiatan pengumpulan data pendukung dilakukan dengan cara observasi lapangan, kunjungan dan wawancara dengan peternak. Kegiatan observasi lapangan dilakukan untuk mengetahui keadaan kandang, kondisi lingkungan, sistem pemeliharaan dan serta kesehatan ternak yang ada di Desa Suka Mulya. Sementara kegiatan kunjungan dan wawancara dilakukan untuk mengetahui karakteristik peternak. 


\section{Analisis Data}

Data berbagai jenis dikumpulkan melalui wawancara serta oservasi di lapangan. Analisis data ditujukan untuk menjawab tujuan penelitian. Semua informasi dan data yang terkumpul ditabulasi sesuai katagori datanya. Kemudian ditetapkan nilai rataan dan standar deviasi menggunakan Sofware Microsoft Office Excel.

\section{HASIL DAN PEMBAHASAN}

Hasil pengukuran keadaan suhu dan kelembaban udara Desa Suka Mulya selama penelitian dapat dilihat pada Tabel 4 dan Tabel 5.

Suhu dan kelembaban adalah faktor yang perlu diperhatikan dalam pemeliharaan sapi perah, karena suhu berpengaruh pada produksi dan kualitas susu (Saleh, 2004). Termometer dan Hygrometer yaitu alat untuk mengukur suhu udara dan kelembaban, baik di ruang tertutup ataupun di luar ruangan.

Tabel. 4. Keadaan Suhu Udara dalam Kandang Sapi Perah PFH di Desa Suka Mulya

\begin{tabular}{|c|c|c|c|c|c|c|}
\hline \multirow[b]{2}{*}{ Jadwal } & \multirow[b]{2}{*}{ Jam } & \multicolumn{4}{|c|}{ Suhu Udara dalam Kandang } & \multirow[b]{2}{*}{ Rataan } \\
\hline & & $\begin{array}{c}\text { Analisa } \\
\text { ke-1 }\end{array}$ & $\begin{array}{c}\text { Analisa } \\
\text { ke-2 }\end{array}$ & $\begin{array}{c}\text { Analisa } \\
\text { Ke-3 }\end{array}$ & $\begin{array}{c}\text { Analisa } \\
\text { Ke-4 }\end{array}$ & \\
\hline Pagi & 07.00 & $29^{\circ} \mathrm{C}$ & $28^{\circ} \mathrm{C}$ & $27^{\circ} \mathrm{C}$ & $29^{\circ} \mathrm{C}$ & $28.25^{\circ} \mathrm{C}$ \\
\hline Siang & 12.00 & $34^{\circ} \mathrm{C}$ & $31^{\circ} \mathrm{C}$ & $32^{\circ} \mathrm{C}$ & $32^{\circ} \mathrm{C}$ & $32.25^{\circ} \mathrm{C}$ \\
\hline Sore & 18.00 & $30^{\circ} \mathrm{C}$ & $29^{\circ} \mathrm{C}$ & $28^{\circ} \mathrm{C}$ & $27^{\circ} \mathrm{C}$ & $28.5^{\circ} \mathrm{C}$ \\
\hline Malam & 00.00 & $28^{\circ} \mathrm{C}$ & $27^{\circ} \mathrm{C}$ & $27^{\circ} \mathrm{C}$ & $26^{\circ} \mathrm{C}$ & $27^{\circ} \mathrm{C}$ \\
\hline Total & & $121^{\circ} \mathrm{C}$ & $115^{\circ} \mathrm{C}$ & $114^{\circ} \mathrm{C}$ & $114^{\circ} \mathrm{C}$ & $116^{\circ} \mathrm{C}$ \\
\hline Rataan & & $30,25^{\circ} \mathrm{C}$ & $28,75^{\circ} \mathrm{C}$ & $28,5^{\circ} \mathrm{C}$ & $28,5^{\circ} \mathrm{C}$ & $29^{\circ} \mathrm{C}$ \\
\hline
\end{tabular}

Sumber: Data Primer diolah, 2015

Tabel. 5. Keadaan Kelembaban Udara dalam Kandang Sapi Perah di Desa Suka Mulya

\begin{tabular}{|c|c|c|c|c|c|c|}
\hline \multirow[b]{2}{*}{ Jadwal } & \multirow[b]{2}{*}{ Jam } & \multicolumn{4}{|c|}{ Kelembaban Udara dalam Kandang } & \multirow[b]{2}{*}{ Rataan } \\
\hline & & $\begin{array}{c}\text { Analisa } \\
\text { ke-1 }\end{array}$ & $\begin{array}{c}\text { Analisa } \\
\text { ke-2 }\end{array}$ & $\begin{array}{c}\text { Analisa } \\
\text { Ke-3 }\end{array}$ & $\begin{array}{c}\text { Analisa } \\
\text { Ke-4 }\end{array}$ & \\
\hline Pagi & 07.00 & $24 \%$ & $25 \%$ & $25 \%$ & $25 \%$ & $24.75 \%$ \\
\hline Siang & 12.00 & $22 \%$ & $23 \%$ & $24 \%$ & $23 \%$ & $23 \%$ \\
\hline Sore & 18.00 & $23 \%$ & $24 \%$ & $23 \%$ & $24 \%$ & $23.5 \%$ \\
\hline Malam & 00.00 & $27 \%$ & $29 \%$ & $24 \%$ & $26 \%$ & $26.5 \%$ \\
\hline Total & & $96 \%$ & $101 \%$ & $96 \%$ & $98 \%$ & $97.75 \%$ \\
\hline Rataan & & $24 \%$ & $25,25 \%$ & $24 \%$ & $24,5 \%$ & $24,4 \%$ \\
\hline
\end{tabular}

Sumber: Data Primer diolah, 2015

Dari kedua tabel dapat dilihat bahwa rataan suhu udara dalam kandang sapi perah PFH yang dipelihara di desa Suka Mulya adalah $29^{\circ} \mathrm{C}$, dengan kisaran $27^{\circ} \mathrm{C}$ sampai $32^{\circ} \mathrm{C}$. Rataan kelembaban udara dalam kandang sapi perah $\mathrm{PFH}$ di Desa Suka Mulya adalah 24,4\% dengan kisaran 22\% sampai 29\%, keadaan ini lebih rendah dari keadaan kelembaban udara yang ideal untuk sapi perah seperti yang disampaikan oleh Sutardi (1985) yaitu 55\%. Rendahnya kelembaban udara ini disebabkan oleh tingginya radiasi matahari dan suhu udara sehingga penguapan air semakin banyak. 


\section{Tata Laksana Pemeliharaan Ternak Sapi Peranakan Fries Holland (PFH) di Peternakan Rakyat Desa Suka Mulya.}

Tata laksana pemeliharaan yang baik akan membawa hasil yang baik terhadap usaha peternakan sapi perah. Tata laksana pemeliharaan sapi perah meliputi tatalaksana kandang dan peralatan, perawatan, kesehatan, penyakit dan pengolahan pasca panen. Tata laksana pemeliharaan sapi perah di peternakan rakyat Desa Suka Mulya dapat dilihat pada Tabel 6.

Tabel. 6. Tata Laksana Pemeliharaan Sapi Perah di desa Suka Mulya

\begin{tabular}{lll}
\hline No. & Sistem Perkandangan & Hasil Pengamatan \\
\hline 1. & Pemeliharaan & Secara intensive \\
2. & Kepemilikan kandang & Kelompok \\
3. & Bentuk kandang & Individu \\
4. & Luas kandang & $10 \times 20 \mathrm{~m}$ \\
5. & Frekuensi pembersihan & 2 kali perhari \\
6. & Waktu pembersihan & Pagi dan sore \\
\hline No. & Pemberian Pakan dan Minum & Hasil Pengamatan \\
\hline 1. & Sumber rumput & Di sekitar lokasi peternakan \\
2. & Jenis hijauan & Rumput gajah \\
3. & Rataan hijauan per ekor & 30 Kg \\
4. & Frekuensi pemberian & 2 kali per hari \\
5. & Jenis konsentrat & Dedak padi \\
6. & Frekuensi pemberian & Tidak teratur \\
7. & Pemberian air minum & 1 ember/ekor \\
\hline No. & Identitas Sapi & Hasil Pengamatan \\
\hline 1. & Asal bibit & Pemerintah \\
2. & Hal apa yang pernah dicatat & Tidak ada \\
3. & Cara identitas sapi & Penomoran \\
\hline
\end{tabular}

Sumber: Data Primer diolah, 2015

Dari tabel tersebut dapat dilihat bahwa tata laksana pemeliharaan sapi perah PFH di desa Suka Mulya, Kecamatan Lembah Seulawah, Kabupaten Aceh Besar termasuk kedalam sistem pemeliharaan secara intensive, dimana ternak dikandangkan secara terus menerus. Akan tetapi dalam pemberian pakan dapat dikatakan masih belum baik, karena hanya hijauan yang diberikan secara rutin, sementera konsentrat hanya diberikan sekali-sekali, dan hanya terdiri dari satu jenis saja, yaitu dedak padi. Dalam pemberian air minum juga masih sangat terbatas, yaitu 1 (satu) ember/ekor/hari, sementara untuk sapi perah seharusnya air minum diberikan secara ad libitum untuk memenuhi kebutuhan produksi susu.

Pencatatan (recording) belum dilakukan oleh peternak di peternakan sapi perah PFH desa Suka Mulya, seperti pencatatan produksi susu, konsumsi pakan dan reproduksi, ini dikarenakan masih minimnya pengetahuan akan pentingnya recording dalam usaha peternakan sapi perah.

Sistem perkawinan ternak yang dilakukan sudah secara Inseminasi Buatan (IB).Semen dan inseminatornya berasal dari Dinas Kesehatan Hewan dan Peternakan Kabupaten Aceh Besar.Penanganan kelahiran ditangani oleh peternak 
sendiri. Manajemen pascalahir belum dilakukan secara baik, sehingga ada beberapa kasus kematian pedet di peternakan tersebut, seperti pemberian susu untuk pedet belum dilakukan secara higienis.

Pemerahan susu yang dilakukan di peternakan sapi perah PFH di desa Suka Mulya dilakukan secara manual. Produksi susu belum dipasarkan, dan belum dilakukan prosedur pasca panen yang higienis. Peternak juga belum melakukan pengolahan susu lebih lanjut.

Penanganan kesehatan yang dilakukan adalah pemberian vitamin, obat cacing dan pengobatan pada sapi-sapi yang terkena penyakit scabies, sementara itu vaksinasi dan penyemprotan kandang masih belum dilakukan.

\section{Karakteristik Responden di Peternakan Rakyat Desa Suka Mulya}

Desa Suka Mulya memiliki daya dukung sumber daya manusia yang cukup baik untuk pengembangan peternakan khususnya peternakan sapi perah. Karakteristik peternak sapi perah di Desa Suka Mulya ditunjukkan pada Tabel 7. Peternak dilihat dari segi usia tergolong produktif, dimana $50 \%$ peternak berusia antara 30-39 tahun, kondisi ini memberikan harapan yang cukup baik terhadap dunia peternakan terbukti dengan banyaknya peternak yang berusia muda.

Tabel 7. Karakteristik Responden Peternak Sapi Perah di Desa Suka Mulya

\begin{tabular}{|c|c|c|c|}
\hline & Karakteristik & Jumlah (orang) & Persentase \\
\hline \multirow[t]{4}{*}{ a. } & Umur peternak & & \\
\hline & $20-29$ tahun & 3 & $30 \%$ \\
\hline & 30-40 tahun & 5 & $50 \%$ \\
\hline & 40-49 tahun & 2 & $20 \%$ \\
\hline \multirow[t]{4}{*}{ b. } & Pendidikan Formal & & \\
\hline & SD & 2 & $20 \%$ \\
\hline & SMP & 2 & $20 \%$ \\
\hline & SMA & 6 & $60 \%$ \\
\hline \multirow[t]{4}{*}{ c. } & Pengalaman beternak & & \\
\hline & $<5$ tahun & 10 & $100 \%$ \\
\hline & $6-10$ tahun & 0 & 0 \\
\hline & $11-15$ tahun & 0 & 0 \\
\hline
\end{tabular}

Sumber: Data Primer diolah, 2016

Pengalaman akan mempengaruhi kemampuan seorang peternak dalam mengelola peternakannya. Semakin banyak pengalaman peternak biasanya semakin besar pula kemampuannya dalam beternak (Kurnadi, 2002). Pengalaman beternak responden di peternakan rakyat desa Suka Mulya masih sedikit, yaitu baru dibawah 5 tahun.

Menurut Fitrianti (2003), faktor yang sangat berpengaruh dalam hal pengetahuan tata cara beternaksapi perah adalah pengalaman dan pendidikan peternak. Pengalaman yang banyak akan semakin baik bila ditunjang dengan pendidikan yang cukup. Berdasarkan hasil wawancara diperoleh bahwa gambaran pendidikan peternak sapi perah sangat beragam. Sebagian responden hanya berpendidikan formal sampai tingkat Sekolah Dasar 20\%, sekitar 20\% responden berpendidikan sampai jenjang SLTP, sebanyak 60\% responden lulusan SLTA. 
Pekerjaan responden terbesar adalah sebagai petani yaitu sebanyak 7 orang (70\%), tukang bangunan 1 orang dan usaha utama ternak perah 2 orang. Data tersebut menggambarkan bahwa beternak hanya sebagai pekerjaan sampingan. Tingginya persentase jumlah responden yang memiliki pekerjaan sebagai petani memberikan gambaran bahwa sektor peternakan dan pertanian tidak dapat dipisahkan dimana keduanya akan bekerja saling terkait.

\section{Kondisi Faali}

Sistem faali yang meliputi respirasi, pulsus, dan temperatur rektal merupakan suatu parameter yang digunakan untuk mengetahui kondisi atau keadaan kesehatan suatu ternak yang dapat dilakukan dengan percobaan langsung (Galem et al., 2012). Status faali ternak merupakan indikasi dari kesehatan dan adaptasi ternak terhadap lingkungannya. Ternak akan selalu beradaptasi dengan lingkungan tempat hidupnya, apabila lingkungan dengan suhu dan kelembaban yang tinggi dapat menyebabkan stress (cekaman) karena sistem pengaturan panas tubuh dengan lingkungannya menjadi tidak seimbang (Ghalem et al., 2012). Ternak domba termasuk hewan homoitherm yang memiliki kemampuan untuk mempertahankan suhu tubuhnya agar tetap stabil, sehingga terjadi keseimbangan antara panas yang diproduksi dengan panas yang dikeluarkan kesekelilingnya (Galem et al., 2012).

\section{Frekuensi Pernafasan}

Respirasi berfungsi sebagai parameter yang dapat digunakan sebagai pedoman untuk mengetahui fungsi organ sampai organ tubuh bekerja secara normal. Fungsi utama pada respirasi yaitu menyediakan oksigen bagi darah dan mengambil karbondioksida dari darah (Frandson, 1992). Frekuensi pernafasan sapi perah PFH di sajikan pada Tabel 8.

Tabel 8. Frekuensi Pernafasan Sapi Perah PFH di Desa Suka Mulya (kali/menit)

\begin{tabular}{|c|c|c|c|c|}
\hline \multirow{2}{*}{ No. Sapi } & \multicolumn{3}{|c|}{ Pengukuran } & \multirow{2}{*}{ Rataan/ekor } \\
\hline & Minggu I & Minggu II & Minggu III & \\
\hline 1 & 27 & 27 & 28 & 27,33 \\
\hline 2 & 29 & 29 & 28 & 28,67 \\
\hline 3 & 27 & 27 & 27 & 27,00 \\
\hline 4 & 27 & 28 & 27 & 27,33 \\
\hline 5 & 28 & 27 & 28 & 27,67 \\
\hline 6 & 29 & 28 & 28 & 28,33 \\
\hline 7 & 28 & 28 & 27 & 27,67 \\
\hline 8 & 29 & 29 & 28 & 28,67 \\
\hline 9 & 29 & 28 & 28 & 28,33 \\
\hline 10 & 30 & 29 & 29 & 29,33 \\
\hline 11 & 27 & 28 & 28 & 27,67 \\
\hline 12 & 27 & 28 & 29 & 28,00 \\
\hline 13 & 29 & 27 & 29 & 28,33 \\
\hline Rataan & 28,15 & 27,92 & 28,00 & 28,03 \\
\hline Standar Deviasi & $\mathbf{1 , 0 3}$ & 0,73 & 0,68 & 0,63 \\
\hline
\end{tabular}

Dari tabel di atas dapat diketahui bahwa rataan frekuensi pernapasan sapi

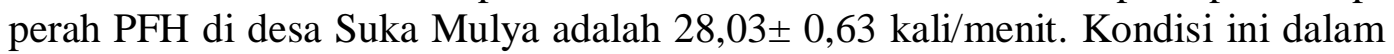
keadaan normal, seperti yang disampaikan Frandson (1996) bahwa frekuensi 
pernafasan sapi perah dalam kondisi normal adalah berkisar antara 24$37 \mathrm{kali} /$ menit. Penelitian Utomo et al. (2009) menunjukkan bahwa rataan frekuensi pernapasan sapi perah pada peternakan rakyat adalah 26,82 kali/menit serta Araby dan Fitri (2009) menyampaikan frekuensi pernapasan sapi perah PFH adalah $29,09 \mathrm{kali} /$ menit. Sementara itu Palulungan et al. (2013) mendapat hasil yang lebih tinggi yaitu $33,56 \mathrm{kali} /$ menit pada suhu kandang $29,41^{\circ} \mathrm{C}$.

\section{Frekuensi Denyut Jantung}

Frekuensi denyut jantung sapi perah PFH di desa Suka Mulya disajikan pada Tabel 9. Dari tabel dapat dilihat bahwa rataan frekuensi denyut jantung adalah $68,92 \pm 0,71 \mathrm{kali} / \mathrm{menit}$.

Tabel 9. Frekuensi Denyut Jantung Sapi Perah PFH di Desa Suka Mulya (kali/menit).

\begin{tabular}{ccccc}
\hline \multirow{2}{*}{ No. Sapi } & \multicolumn{3}{c}{ Pengukuran } & \multirow{2}{*}{ Rataan/ekor } \\
\cline { 2 - 4 } & Minggu I & Minggu II & Minggu III & \\
\hline 1 & 67 & 67 & 69 & 67,67 \\
2 & 70 & 68 & 68 & 68,67 \\
4 & 70 & 69 & 69 & 69,33 \\
5 & 69 & 70 & 70 & 69,67 \\
6 & 70 & 68 & 69 & 69,00 \\
7 & 69 & 69 & 67 & 68,33 \\
8 & 68 & 60 & 69 & 69,00 \\
9 & 68 & 69 & 69 & 68,33 \\
10 & 69 & 72 & 71 & 69,67 \\
11 & 70 & 68 & 69 & 70,33 \\
12 & 69 & 69 & 70 & 69,00 \\
13 & 67 & $\mathbf{6 0}$ & 68 & 68,00 \\
Rataan & 68,85 & 69,00 & 68 & 69,00 \\
\hline Standar deviasi & 1,03 & 1,24 & 1,00 & 68,92 \\
\hline
\end{tabular}

Sumber: Data Primer diolah, 2015

Frekuensi denyut jantung sapi PFH yang sehat pada daerah nyaman adalah 60/70 kali/menit, reaksi sapi PFH terhadap perubahan suhu yang dilihat dari respons pernafasan dan denyut jantung merupakan mekanisme dari tubuh sapi untuk mengurangi atau melepaskan panas yang diterima dari luar tubuh ternak (Yani dan Purwanto,2006). Frekuensi denyut jantung sapi perah PFH yang dipelihara pada peternakan rakyat di desa Kembang, Boyolali, adalah 70,54 kali/menit pada keadaan suhu udara kandang $23,94^{\circ} \mathrm{C}$ (Utomo, et al., 2009). Menurut Araby dan Fitri (2009) frekuensi denyut jantung sapi PFH yang dipelihara di peternakan rakyat Cipelang, Bogor adalah 63,64 kali/menit pada suhu udara berkisar antara $23-30^{\circ} \mathrm{C}$. Sementara itu menurut Palulungan, et al. (2013), frekuensi denyut jantung sapi PFH pada suhu udara dalam kandang $29,41^{\circ} \mathrm{C}$ adalah $68,44 \mathrm{kali} /$ menit. Berdasarkan paparan di atas dapat dikatakan bahwa frekuensi denyut jantung sapi PFH di desa Suka Mulya dalam keadaan normal. 


\section{Temperatur Rektal}

Temperatur tubuh merupakan hasil keseimbangan antara produksi panas dan pelepas panas tubuh. Faktor-faktor yang mempengaruhi temperatur tubuh antara lain bangsa ternak, aktivitas ternak, kondisi kesehatan ternak, dan kondisi lingkungan ternak (Frandson, 1996). Temperatul rektal sapi perah PFH disajikan pada Tabel 10.

Tabel 10. Suhu Rektal Sapi Perah PFH di Desa Suka Mulya $\left({ }^{\circ} \mathrm{C}\right)$

\begin{tabular}{|c|c|c|c|c|}
\hline \multirow{2}{*}{ No. Sapi } & \multicolumn{3}{|c|}{ Pengukuran } & \multirow{2}{*}{ Rataan/ekor } \\
\hline & Minggu I & Minggu II & Minggu III & \\
\hline 1 & 36,4 & 37,3 & 35,9 & 36,53 \\
\hline 2 & 37,3 & 37,4 & 37,3 & 37,33 \\
\hline 3 & 36,4 & 35,7 & 37,4 & 36,50 \\
\hline 4 & 33,6 & 36,6 & 37,3 & 35,83 \\
\hline 5 & 37,3 & 37,5 & 36,5 & 37,10 \\
\hline 6 & 35,8 & 36,5 & 36,6 & 36,30 \\
\hline 7 & 37,9 & 36,8 & 35,2 & 36,63 \\
\hline 8 & 36,5 & 35,7 & 35,4 & 35,87 \\
\hline 9 & 35,9 & 36,4 & 37,4 & 36,57 \\
\hline 10 & 37,3 & 33,6 & 35,7 & 35,53 \\
\hline 11 & 37,4 & 37,3 & 36,6 & 37,10 \\
\hline 12 & 37,3 & 35,8 & 37,5 & 36,87 \\
\hline 13 & 36,5 & 37,9 & 37,3 & 37,23 \\
\hline Rataan & 36,58 & 36,50 & 36,62 & 36,57 \\
\hline Standar deviasi & 1,06 & 1,09 & $\mathbf{0 , 8 0}$ & $\mathbf{0 , 5 5}$ \\
\hline
\end{tabular}

Sumber: Data Primer diolah, 2015

Dari Tabel 10 diperlihatkan bahwa rataan temperatur rektal sapi perah PFH di desa Suka Mulya adalah $36,57 \pm 0,55^{\circ} \mathrm{C}$. Kondisi ini sejalan dengan hasil yang disampaikan Utomo, et al. (2009) yaitu $36,33^{\circ} \mathrm{C}$ pada suhu udara dalam kandang $23,94^{\circ} \mathrm{C}$. Keadaan ini masih berada dibawah hasil penelitian Palulungan et al. (2013) pada sapi $\mathrm{PFH}$ yaitu $38,82^{\circ} \mathrm{C}$ pada suhu udara dalam kandang $29,41^{\circ} \mathrm{C}$, serta Araby dan Fitri (2009) yang menyampaikan temperatul rektal sapi perah PFH di Cipelang, Bogor yaitu $38,50^{\circ} \mathrm{C}$.

\section{KESIMPULAN DAN SARAN}

Berdasarkan hasil penelitian yang telah dilakukan terhadap sapi perah PFH di desa Suka Mulya pada suhu udara dalam kandang $29^{\circ} \mathrm{C}$ dan kelembaban $24,4 \%$, dapat disimpulkan bahwa kondisi faali yang meliputi frekuensi pernapasan $(28,03 \pm 0,63 \mathrm{kali} /$ menit $)$, frekuensi denyut jantung $(68,92 \pm 0,71 \mathrm{kali} / \mathrm{menit}) \mathrm{dan}$ temperatur $\operatorname{rektal}\left(36,57 \pm 0,55^{\circ} \mathrm{C}\right)$ dalam kondisi normal. Sehingga dapat dikatakan Sapi Peranakan fries Holland (PFH) dapat beradaptasi dengan lingkungan. Untuk meningkatkan potensi sapi perah PFH di desa Suka Mulya perlu diadakan pembinaan lebih lanjut kepada peternak baik oleh instansi pemerintah maupun akademisi, sehingga dapat terwujud sentra peternakan sapi 
perah PFH di Desa Suka Mulya, Kecamatan Lembah Seulawah, Kabupaten Aceh Besar.

\section{DAFTAR PUSTAKA}

Aceh, D.A. 2010. Gambaran Umum Kabupaten Aceh Besar. http/l/.google.com. Akses pada: 03 November 2015.

Araby, D. dan Fitri, C.A., Kajian Fisiologi Penggunaan Bovine Somatotropi $n$ (bST) pada Sapi Pra Afkir. Jurnal Agripet Vo. (9) No. 2:42 - 48.

Blakely, J and D.H. Bade. 1991. Ilmu Peternakan, edisi ke- 4. Gadjah Mada University Press. Jogjakarta.

Fitrianti, A. T. 2003. Penampilan Reproduksi Sapi Perah di Peternakan Sapi Perah Rakyat Wilayah Kerja KUDMojosongo Kabupaten Boyolali, Jawa Tengah. Skripsi. Fakultas KedokteranHewan Institut Pertanian Bogor.

Frandson R. D., W. L. Wilke and A. D. Fails. 2009. Anatomy and Physiology of Farm Animals. Wiley-Blackwell. Lowa.

Ghalem, S., N. Khebichat, K. Nekkaz. 2012. The Physology of Anima $l$ Respiration: Study of Domestic Animal. Article ID 737271, 8 pages. doi: 11. 1133per2012per7372721.

Palulungan, J.A., Adiarto, Hartatik, T. 2013. Pengaruh Kombonasi Pengkabutan dan Kipas Angin terhadap Kondisi Fisiologis Sapi Perah Peranakan Friesian Holland. Buletin Peternakan Vol. 37(3): 189-197. Oktober 2013.

Saleh, E. 2004. Dasar Pengolahan Susu dan Hasil Ikutan Ternak. Program Studi Produksi Ternak Fakultas Pertanian Universitas Sumatera Utara.

Sientje. 2003. Stres Panas pada Sapi Perah Laktasi. Institut Pertanian Bogor.

Sutardi, T. 1981. Sapi Perah dan Pemberian Makanannya. Departemen Ilmu Makanan Ternak Fakultas Peternakan Institut Pertanian Bogor (unpublished).

Utomo, B., D.P. Miranti dan G.C. Intan (2009). Kajian Termoregulasi Sapi Perah Periode Laktasi dengan Introduksi Teknologi Peningkatan Kualitas Pakan.Seminar Hasil Penelitian Peternakan dan Veteriner. Balai Pengkajian Teknologi Pertanian Jawa Tengah, Bukit Tegalepek, Sidomulyo, Ungaran. Hal.263-268.

Yani, A dan B. P. Purwanto. 2006. Pengaruh Iklim Mikro Terhadap Respons Fisiologis SapiPeranakan Fries Holland dan Modifikasi Lingkungan Untuk Meningkatkan Produktivitasnya. Media Peternakan 29 (1): 35-46. 